\title{
Editorial Introduction to the Supplement "Diagnosis of Infectious Diseases by Detection of Microbial Pathogens: A Joint Session Between HemoSpec FrameWork 7 Consortium with COST Action BM1401 Raman4Clinics Working Group 2"
}

Evangelos J. Giamarellos-Bourboulis

Received: February 9, 2018

(C) The Author(s) 2018. This article is an open access publication

\section{INTRODUCTION}

According to the Sepsis-3 definitions, sepsis is nowadays defined as a life-threatening organ dysfunction due to the dysregulated host response to an infection [1]. The mainstay of management relies on the prompt recognition of the septic patient, since final outcome much depends on the time of start of antimicrobials. More precisely, a retrospective survey in 2713 patients with septic shock showed that final survival was $79.1 \%$ for those starting adequate antimicrobial therapy within the first $1 \mathrm{~h}$ from the advent of hypotension; the chances for survival were decreasing by $7.6 \%$ for every hour of delay of the start of antimicrobial therapy [2]. However, the efficacy of an early start of antimicrobials relies on the susceptibility of empirically administered antimicrobials on the implicated pathogens. Until now, microbiology techniques cannot provide information on the pathogen and susceptibility pattern in less than an hour. Even more, the likelihood of sepsis due to infection by resistant isolates which is emerging

Enhanced content To view enhanced content for this article go to https://doi.org/10.6084/m9.figshare. 5873811 .

E. J. Giamarellos-Bourboulis ( $\square)$

4th Department of Internal Medicine, National and Kapodistrian University of Athens, Medical School, Athens, Greece

e-mail: egiamarel@med.uoa.gr globally is generating the question as to what antimicrobial should be administered as early treatment. Although information coming from the epidemiology of the patient, such as recent hospitalization, intake of antibiotics in the last 3 months and residence in a long-term care facility, may help in assessing the risk of infection of the patient by multidrug-resistant isolates [3], there are many patients with infections acquired inside the intensive care unit caused by extensive drug-resistant or pandrug-resistant isolates.

This leads to two unmet medical needs: (1) early recognition of the septic patient, and (2) early recognition of the pathogen and the evaluation of its susceptibilities to antimicrobials. Raman4Clinics is a consortium of experts funded by the COST European initiative aimed at education towards the development of the Raman photonic technology for medical diagnostics. Part of this initiative is dedicated to the diagnostics of severe infections. This initiative also interacts with the FrameWork 7-funded European consortium, HemoSpec. The goal of HemoSpec is to develop a device that integrates information coming from the measurement of serum biomarkers and Raman microscopy of circulating white blood cells for the early diagnosis of sepsis.

Raman4Clinics organized a session during the Conference of the Hellenic Sepsis Study Group on June 18, 2017, at Kalamata, Greece. The session hosted a presentation for the 
conduct of the INTELLIGENCE- 1 which that is a prospective study running at five sites in Greece on the diagnostic performance of the HemoSpec device for sepsis (ClinicalTrials.gov NCT03306186). The session also hosted three presentations which are also published in this supplement of the journal. These presentations are representative of the rationale of the developing collaboration in Rama4Clinics, i.e. the interaction between clinicians and biologists. To this end, one presentation was dedicated to the use of Raman microscopy for the recognition of the diversity of fungi, and two presentations were on the determinants of the endothelial dysfunction of the host in sepsis.

\section{ACKNOWLEDGEMENTS}

Funding. This article is based upon work from COST Action "Raman-based applications for clinical diagnostics-Raman4Clinics" (BM 1401), supported by COST (European Cooperation in Science and Technology). No funding or sponsorship was received for the publication of the article.

Authorship. The named author meets the International Committee of Medical Journal Editors (ICMJE) criteria for authorship for this article, takes responsibility for the integrity of the work as a whole, and has given approval for this version to be published.

Disclosures. Evangelos J. Giamarellos-Bourboulis has received honoraria (paid to the University of Athens) from AbbVie, Biotest, Brahms GmbH, and The Medicines Company; has received compensation as a consultant for Astellas Greece and for XBiotech (paid to the
University of Athens); and has received independent educational grants (paid to the University of Athens) from AbbVie, InflaRx and Sanofi. He is funded by the FrameWork 7 program HemoSpec and by the Horizon 2020 Marie-Curie grant European Sepsis Academy (granted to the University of Athens).

Compliance with Ethics Guidelines. This article does not contain any studies with human participants or animals performed by any of the authors.

Open Access. This article is distributed under the terms of the Creative Commons Attribution-NonCommercial 4.0 International License (http://creativecommons.org/licenses/ by-nc/4.0/), which permits any noncommercial use, distribution, and reproduction in any medium, provided you give appropriate credit to the original author(s) and the source, provide a link to the Creative Commons license, and indicate if changes were made.

\section{REFERENCES}

1. Singer M, Deutschman CS, Seymour CW, et al. The third international consensus definitions for sepsis and septic shock (sepsis-3). JAMA. 2016;315(8):801-10.

2. Kumar A, Roberts D, Wood KE, et al. Duration of hypotension before initiation of effective antimicrobial therapy is the critical determinant of survival in human septic shock. Crit Care Med. 2006;34(6):1589-96.

3. Koupetori M, Retsas T, Antonakos N, et al. Bloodstream infections and sepsis in Greece: over-time change of epidemiology and impact of de-escalation on final outcome. BMC Infect Dis. 2014;14:272. 